\title{
7.4. О ВОЗМОЖНОСТИ РАЗВИТИЯ СИСТЕМЫ БИЗНЕС- ПРОЦЕССОВ КРУПНОГО ПРОМЫШЛЕННОГО ПРЕДПРИЯТИЯ В ОБЛАСТИ СНАБЖЕНИЯ
}

Штейнгарт Е.А., ассистент,

Высшая школа сервиса и торговли;

Бурмистров А.Н., к.э.Н., доцент,

Высшая школа сервиса и торговли

Высшая школа сервиса и торговли, Санкт-Петербургский политехнический университет им. Петра Великого, г. Санкт-Петербург

В современном мире возрастает уровень конкуренции и скорость происходящих изменений, увеличивается разнообразие макро и микроэкономических факторов, существенно влияющих на деятельность хозяйствующих субъектов, усложняется их взаимодействие и изготавливаемая продукция. Наиболее остро эти обстоятельства проявляются в процессе функционирования крупных промышленных предприятий РФ, характеризующихся значительными масштабами деятельности, сложным внутренним устройством и многообразием взаимодействий и взаимосвязей во внутренней и внешней среде. При этом область снабжения отечественных крупных промышленных предприятий является сейчас одной из самых проблемных и нестабильных, одновременно являясь и одной из ключевых составляющих для достижения эффективной и успешной производственной деятельности. В этих непростых условиях необходимо искать резервы улучшения функционирования рассматриваемых предприятий, в частности использовать различные организационные инновации, одной из которых является концепция архитектуры предприятия и совершенствования системы бизнес-процессов.

\section{Литература}

1. О развитии малого и среднего предпринимательства в РФ [Электронный ресурс] : фредер. закон от 24 июля 2007 г. №209-Ф3 (ред. от 29 июня 2015 г.). Доступ из справ.-правовой системы «Консультант Плюс».

2. О государственном оборонном заказе [Электронный ресурс] : федер. закон от 29 дек. 2012 г. №275. Доступ из справ.правовой системы «Консультант Плюс».

3. О внесении изменений в Федеральный закон №275 о ГОЗ и отдельные законодательные акты РФ [Электронный ресурс] : федер. закон от 29 июня 2015 г. №159. Доступ из справ.-правовой системы «Консультант Плюс».

4. О предельных значениях выручки от реализации товаров (работ, услуг) для каждой категории субъектов малого и среднего предпринимательства [Электронный ресурс] : постановление Правительства РФ от 13 июля 2015 г. №702. Доступ из справ.-правовой системы «Консультант Плюс».

5. Распоряжение Правительства РФ от 20 авг. 2009 г. №1226-Р (ред. от 15 мая 2015 г.) [Электронный ресурс]. Доступ из справ.-правовой системы «Консультант Плюс».

6. Приказ Мин-ва промышленности и торговли РФ от 3 июля 2015 г. №1828 [Электронный ресурс]. Доступ из справ.правовой системы «Консультант Плюс».

7. Промышленные автоматизированные системы. Требования к стандартным архитектурам и методологиям предприятия [Электронный ресурс] : ГОСТ Р ИСО 15704-2008. Доступ из справ.-правовой системы «Кодекс».

8. Интеграция систем управления предприятием. Часть 1. Модели и терминология [Электронный ресурс] : ГОСТ Р МЭК 62264-1-2010. Доступ из справ.-правовой системы «Кодекс».

9. Интеграция предприятий. Основа моделирования предприятий [Электронный ресурс] : ГОСТ Р ИСО 19439-2008. Доступ из справ.-правовой системы «Кодекс».

10. 33 судоремонтный завод [Электронный ресурс] : официальный сайт AO. - URL : http://xn--33-ulc9ae.xn--p1ai/wpcontent/uploads/2017/02/Reestr-kooperatsii-v-ram kah-GK-----1617187303851432209010431-ot-30.03.2016-g.pdf

11. Бурмистров А.Н. Методика оценки экономической эффективности от проектирования системы бизнес-процессов в архитектуре крупного промышленного предприятия [Текст] / А.Н. Бурмистров, Е.А. Штейнгарт // Актуальные проблемы современного общества : Социология. Управление. Политика : межвуз. сб. науч. тр. / под. ред. Э.Б. Аваковой. - СПб. : Изд-во СПБГЭУ, 2019. - С. 85-101.

12. Бурмистров А.Н. О терминологии и основных положениях методологии разработки функционального представления архитектуры предприятия [Текст] / А.Н. Бурмистров // Стратегическое управление организациями: технологии управления : сб. науч. тр. науч. и учеб.-практ. конф. - СПб. : Изд-во Политехн. ун-та, 2017. - С. 14-27.

13. Гаврилов Ю. Эксперты разошлись в оценке нового стратегического комплекса [Электронный ресурс] // Российская газета : федер. вып. - 2011. - №57. - URL : https://rg.ru/2011/03/18/raketa.html

14. Годовой отчет АО «ЛОМО» [Текст]. - 2002-2018.

15. Кузнецов К.В. Практика размещения государственного оборонного заказа. Первые шаги по новым правилам. ГЭлектронный ресурс] / К.В. Кузнецов. - URL : https://www.kkuznetsov.ru/ 275-fz-goz-article.pdf

16. Национальные проекты: целевые показатели и основные результаты (по состоянию на 7 февр. 2019 г.) [Текст]. - М., 2019. - 110 c.

17. Не брендом единым [Электронный ресурс] // Деловой Петербург. - URL : http://story.dp.ru/rb

18. Петербург и Ленобласть: люди, ресурсы, возможности [Текст] // Деловая карта России. - 2019. - №1. - С. 3-17.

19. Толковый словарь русского языка [Текст] : 80000 слов и фразеологических выражений / Росс. акад. наук ; Ин-т русского языка им. В.В. Виноградова. - 4-е изд., доп. - М. : Азбуковник, 1999. - 944 с.

\section{Ключевые слова}

Система бизнес-процессов; архитектура предприятия; функциональная модель; крупное промышленное предприятие; развитие; снабжение; экономический эфффект. 


\title{
Штейнгарт Евгений Александрович
}

\author{
Бурмистров Андрей Николаевич
}

\section{РЕЦЕНЗИЯ}

Статья Е.А. Штейнгарта, ассистента Высшей школы сервиса и торговли Санкт-Петербургского политехнического университета Петра Великого, и А.Н. Бурмистрова, кандидата экономических наук, доцента Высшей школы сервиса и торговли Санкт-Петербургского политехнического университета Петра Великого, актуальна для формирования понимания о современных проблемах функционирования промышленных предприятий, в частности, в такой первостепенной сфере, как снабжение, и комплексном механизме снижения влияния данных проблем по средствам применения инновационной концепции архитектуры предприятия в части разработки стандартного функционального представления в условиях приоритизации экономики знаний и цифровизации.

Дпя эффективного управления современным промышленным предприятием, особенно крупным, в эпоху ускорения изменений внутренней и внешней среды, воздействия множества фракторов, которые зачастую не поддаются прогнозированию, способность к оперативной трансформации деятельности является, пожалуй, одним из важнейших факторов успеха. Однако в отечественных реалиях осуществление данной трансформации, как правило, сопряжено со значительными трудностями ввиду недостаточной степени автоматизации, стандартизации и регламентации деятельности промышленных предприятий. Традиционные методы и инструменты менеджмента не позволяют разработать функциональную модель (функциональное представление архитектуры) промышленного предприятия с необходимой степенью подробности, за обозримый период времени, идентифицировав полный перечень функциональных единиц. А ведь именно комплексная модель всех работ (действий) осуществляемых на предприятии является основой для дальнейшего реинжиниринга и внесения различных улучшений в работу промышленных предприятий.

Развитие системы бизнес-процессов промышленных предприятий за счет проектирования стандартизированной функциональной модели особенно значимо в сфере снабжения, так как в современных реалиях реализация масштабных наукоемких проектов по проектированию и изготовлению инновационных изделий возможна только за счет многоуровневой кооперации. В рамках данных кооперационных сетей промышленные предприятия выступают в качестве открытых систем, которые, по сути, на взаимовыгодных условиях обмениваются своими ключевыми компетенциями, пытаясь добиться синергетического эффекта и максимизации прибыли.

Логика научного исследования подводит к тому, что преодоление многочисленных и многогранных трудностей в области снабжения промышленности не может быть осуществлено одномоментно и с использованием какой-либо одной методики. Тем не менее, существуют эффективные концепции для снижения негативного влияния обозначенных проблем на деятельность промышленных предприятий.

Вслед за идентификацией проблем и обзором существующих методов их разрешения, приводится организационно-экономическое содержание важнейших понятий исследования, которое дает достаточно полное представление о рассматриваемой предметной области. Далее предложена методика проектирования системы бизнес-процессов и инструменты для ее поддержки (классификатор и кодификатор), которые адекватны цели исследования.

В статье отводится особое место механизму оценки экономической эффективности, в частности акцентируется внимание, на том, что практическая реализация предложенных разработок на конкретном известном крупном промышленном предприятии в области снабжения дала ощутимый положительный эффект.

Статья раскрывает оригинальные идеи авторов по совершенствованию функционирования промышленности и имеет прикладное значение

Выводы в статье Е.А. Штейнгарта, ассистента Высшей школы сервиса и торговли Санкт-Петербургского политехнического университета Петра Великого, и А.Н. Бурмистрова, кандидата экономических наук, доцента Высшей школы сервиса и торговли Санкт-Петербургского политехнического университета Петра Великого, отражают глубокий научный подход к совершенствованию развития систем бизнеспроцессов крупных промышленных предприятий в рамках создания целостной архитектуры предприятия. Проведенные исследования соответствуют современному уровню, а полученные результаты, несомненно, позволят повысить степень автоматизации и стандартизации, а также эффективность и конкурентоспособность отечественных хозяйствующих субъектов. Рецензируемая статья заслуживает положительной оценки, удовлетворяет требованиям, которые предъявляются к научным публикациям в изданиях из перечня Высшей аттестационной комиссии при Министерстве науки и высшего образования РФ, и рекомендуется для публикации в журнале «Аудит и финансовый анализ».

Калинина О.В., д.э.н., профессор Высшей школы сервиса и торговли СПБПУ Петра Великого, заместитель директора по научной работе Института промышленного менеджмента, экономики и торговли, г. Санкт-Петербург.

DOI 10.38097/AFA.2020.20.32.024 